\title{
Team Midterm in an Introductory Process Design Course
}

\author{
Marnie V. Jamieson and John M. Shaw \\ Faculty of Engineering, University of Alberta \\ mvjamies@ualberta.ca and jmshaw@ualberta.ca
}

\begin{abstract}
The introductory design course combines team and individual formative and summative assessment techniques. Individual summative midterm and final examinations were used to assess individual performance. Students were given the opportunity to increase their individual midterm examination marks by rewriting the same examination as a team following the individual summative assessment. This formative exercise provided students with a comparison of the efficacy and quality of teamwork versus individual work, and provided immediate feedback and correction for many conceptual and mechanical errors on the summative midterm examination. This paper reports on the strategy and set up of the midterm examination, the results obtained by individual students and student teams, and learning outcomes (including anecdotal comments from students regarding the experience and reduced time spent reviewing examinations with students) based on two iterations of the course.
\end{abstract}

Keywords: Two Stage Exam, Engineering Education, Formative, Summative, Assessment, Collaborative Learning, Team Examination, CEAB Graduate Assessment Development

\section{INTRODUCTION}

The role of formative assessment and developmental feedback in fostering professional skill performance improvement are seen as critical aspects of course design. Constructive Alignment [2-4] requires assessment and activity designs that are related to learning objectives that actively address what students do to learn and to guide their approach to learn higher-level cognitive task skills [1]. Course sections with high enrolment are in direct opposition to the provision of quality feedback from instructors on multiple formative assignments. However, eliminating assessment linked to student development due to student numbers misses learning opportunities related to key objectives of the engineering undergraduate program, especially the abilities to analyze, synthesize and evaluate contextual information. [1,5]

\subsection{Motivation}

As teamwork is innate to engineering work in design, operation, production and research, the clarification of team learning objectives and simplification of activity execution were identified as opportunities for course and learning enhancement. A two-part midterm with an individual and team component was implemented to foster opportunities for student academic and team skill development.

\subsection{Literature Review}

The development of meaningful learning opportunities to support skill development and demonstration of performance are linked $[12,2,3,4]$. Collaborative Learning techniques and two part exams have been used in multiple contexts $[8,9]$. Two part midterms with an individual assessment component and a team component are an assessment strategy used by the University of British Columbia Physics Department [14] and in Mathematics courses at the University of Alberta delivered by Vincent Bouchard. In both instances the collaborative midterms immediately follow the individual midterms with a weighting split ranging from $25 / 75$ to $15 / 85$. Lively debate and discussion was observed in all cases as students came to consensus during the team midterm. [12] Individual team members took away essentially the same mastery as the level attained by the team as a whole [6].

In a recent assessment meta study [7], Hattie reports the highest ranked factors for teaching or teacher related effects are: formative feedback to teachers (.90), teacher clarity (.75), reciprocal teaching (.74), feedback (.73), spaced vs. mass practice (.71), metacognitive strategies (.69), self-verbalization/self questioning (.64), professional development (.62). All of which require instructor time and attention making them part of the instructor loading equation. By comparison the highest ranked factors for students are: self report grades (1.44) and concentration persistence and engagement (.48) and gender (.12) [7]. Self-reporting of grades is a student prediction of how well they think they can do in the course prior to summative assessment. Formative assessment has been strongly linked to learning [5] and the mastery attained on prior exams may impact self- 
reporting of grades impacting both teacher related and student related assessment effects. Team work and collaboration further encourage metacognition as students think through problem solving in different ways. $[5,11,13]$. Students are well prepared for collaboration as they have prepared for and completed an individual exam where they have thought about and committed to answers and problem solving processes. [14].

\subsection{Problem Definition}

Course sections with high enrolment are in direct opposition to the provision of quality and timely feedback from instructors to students. Formative assessments are intended to enhance learning and summative assessments are intended to evaluate progress. During the term the students benefit from ongoing feedback on their progress and instructors benefit from feedback on student learning gained from summative assessment analysis. Opportunities to increase formative feedback that leverage high impact assessment effects and that are scalable to large class sizes are sought. Their implementation improves student learning and enhances the course over all.

\subsection{Solutions Considered}

Individual midterm examinations provide summative assessments to students and instructors, part way through a course, and signal to students the probability of success in a course. An individual midterm followed by a team midterm provides individual summative assessment and immediate formative feedback to students. Alternate methods for team selection and the grading structure were considered based on $U$ of A (mathematics) and UBC (physics) two-part exam models. However, students selfselect teams in the introductory design course, for both tutorial assignments and design projects. These teams are retained for the team portion of the exam. A grade weighting of 20/80 for collaborative and individual portions of the midterm was selected.

\subsection{Significance}

Both students and instructors haves optimal levels of task loading where performance is excellent and beyond which individuals become overloaded and tired, and performance degrades. That optimal loadings vary among individuals. From observation over the capstone design blended learning study period, items that are negatively affected when instructor loading is high are [10]:

- Quantity and quality of direct feedback to students on formative assignments

- Type and quantity of formative assignments given
- Summative grading procedures

- Time for professional development

- Time for continual course development (clarity, formative evaluation, constructive alignment)

Methodologies that provide the benefits of immediate formative feedback to students while decreasing instructional pressure and workload are "win-win" outcomes for students and instructors. Methodologies that leverage high impact effects on assessment outcomes, student metacognitive development and professional skill development that further CEAB graduate attribute attainment while minimizing instructor loading are priorities.

\section{TEAM MIDTERM DEVELOPMENT}

\subsection{Midterm Exam Assessment}

Introductory design assessment has two equally weighted components: team and individual work. Individual work comprises examinations and quizzes while teamwork includes weekly design lab assignments and a design project. The midterm was formerly classified as an individual component of the course and had a 50 minute duration. This time frame was adopted for the first iteration of the two-part exam in Fa15.

The individual portion of the exam was redeveloped from a short answer problem exam to a multiple-choice exam. The exam was paper-based with an automated scoring answer sheet and written justification for responses selected. Questions were patterned on previous midterms and were aligned with the course learning objectives. Alternative incorrect answers were developed from common mistakes and typically covered a range of numeric possibilities. Individual exams were collected prior to and marked separately from the team midterms.

The team and individual versions of the exam were the same. Teams were given a fresh copy of the exam and 30 minutes to complete it. The individual marks were protected and if the team scored higher the individual mark would be a $80 / 20$ composite of the individual and the team midterm grade.

\subsection{Fall 2015 Exam Structure}

Students were given "pre-released" information regarding the midterm two days prior to the scheduled time. Pre-released information included the exam cover page including exam instructions, section titles, question weighting, sample questions, process descriptions and readings on which questions were based. The midterm was multiple-choice with an automatic scoring sheet. Students were required to justify their answers on the paper exam to earn full credit for a question. The 
automatic scoring answer sheet was used to record and machine grade student answers to the multiple-choice questions. Instructors graded the justifications and awarded part marks for the multiple choice questions and a Block Flow Diagram.. Grading was completed and exams results were returned to students within two days of the exam. The instructors agreed upon the grading methods in advance to ensure consistency.

The Fa 2015 cohort comprised eighty-seven mainly regular stream Chemical Engineering students.

\subsection{Winter 2016 Midterm Structure}

The prelease information and midterm structures were identical to the Fa15 midterm, with different questions and readings of course. For example, a mass balance question was substituted for the Block Flow Diagram preparation question. The individual component of the exam was increased to 90 minutes for Winter 2016 to reduce the time pressure but the midterm was still designed for 50 minutes. The team component of the exam remained 30 minutes. Grading was performed in the same manner, and with the same speed. The mass balance question was reviewed in class. Grading consistency is illustrated in Table 1. The Wi16 cohort comprised seventy-eight mainly co-op stream Chemical Engineering students.

\subsection{Exam Development and Testing}

The midterm and solutions were drafted by one instructor, edited by a second instructor and tested blind by a third instructor. The collaborative nature of exam development served several purposes including fairness evaluation, exam length measurement, and clarity. The Fa15 and the Wi16 midterm were drafted based on the course objectives. The questions provided opportunities for students to demonstrate engagement and mastery of the lecture and lab material. The questions targeted cognitive task areas including analyzing, synthesis and evaluation techniques. The midterm editor reviewed the questions for clarity, assumptions required and stated, and alignment with course objectives and instructional material. The midterm tester sat the exam with the

Table 1: Part Marks Grader Comparison wi2016.

\begin{tabular}{|c|c|c|c|c|}
\hline $\begin{array}{c}\text { Score } \\
\text { (\% Basis) }\end{array}$ & $\begin{array}{c}\text { Grader } \\
\text { A }\end{array}$ & $\begin{array}{c}\text { Grader } \\
\text { B }\end{array}$ & Delta & Class \\
\hline Average & 72.3 & 73.8 & 1.5 & 73.2 \\
\hline $\begin{array}{c}\text { Standard } \\
\text { Deviation }\end{array}$ & 16.3 & 16.1 & 0.2 & 16.1 \\
\hline Minimum & 33.3 & 41.7 & 8.4 & 33.3 \\
\hline Maximum & 100 & 100 & 0 & 100 \\
\hline
\end{tabular}

permitted resources. The tester made notes on their assumptions, the time taken, and unclear areas. The tester and the drafter then discussed the results and made adjustments to the midterm. This work was initiated three to four weeks prior to the midterm to allow for exam printing and delivery deadlines.

\section{RESULTS AND DISCUSSION}

A two-part midterm was implemented for the Fa15 and Wi16 cohorts for introductory design. The individual part for the Fa15 cohort was time constrained. While some students were able to finish most ran out of time and were unable to complete all questions. This version of the individual exam was marked out of 28 instead of 30 to manage the time constraint more fairly to students. Results are reported on this basis. The original 50 minute time frame was retained for exam design but 90 minutes were allowed for the Wi16 individual exam. Both exams were open notes, open textbook, and calculators were allowed. The average for the time-constrained exam was lower by $\sim 10 \%$. Results for both cohorts increased for the collaborative exam and the majority of students increased their midterm grade as a result of the collaborative effort by $10 \%$ for the Fa15 cohort and by $15 \%$ for the Wi16 cohort.

\subsection{Comparison of Individual and Team Results}

The midterm design for the Fa15 cohort included drawing a block flow diagram (BFD) based on a process description provided in the pre-released material. The Wi16 cohort midterm included a Mass Balance (MB) calculation instead of a BFD. Cross plots showing marks for individuals and teams for all students in both cohorts are shown in Figure 1. Statistical summaries showing averages, standard deviations, minimum and maximum marks for individuals and teams are provided in Tables 2 and 3 for the Fall 2015 cohort and in Tables 4 and 5 for the Winter 2016 cohort.

Table 2: Individual Result Summary Fa2015 (50 min).

\begin{tabular}{|c|c|c|c|c|}
\hline $\begin{array}{c}\text { Score } \\
\text { (\% Basis) }\end{array}$ & $\begin{array}{c}\text { Answer } \\
\text { Sheet }\end{array}$ & $\begin{array}{c}\text { Part } \\
\text { Marks }\end{array}$ & BFD & $\begin{array}{c}\text { Test } \\
\text { Total }\end{array}$ \\
\hline Average & 52 & 74 & 74 & 63.6 \\
\hline $\begin{array}{c}\text { Standard } \\
\text { Deviation }\end{array}$ & 17 & 15 & 15 & 13 \\
\hline Minimum & 14 & 32 & 0 & 38.3 \\
\hline Maximum & 86 & 100 & 100 & 90 \\
\hline
\end{tabular}


Table 3: Team Result Summary Fa2015 (30 Min).

\begin{tabular}{|c|c|c|c|c|}
\hline $\begin{array}{c}\text { Score } \\
\text { (\% Basis) }\end{array}$ & $\begin{array}{c}\text { Answer } \\
\text { Sheet }\end{array}$ & $\begin{array}{c}\text { Part } \\
\text { Marks }\end{array}$ & BFD & $\begin{array}{c}\text { Test } \\
\text { Total }\end{array}$ \\
\hline Average & 77.6 & 89.8 & 80.7 & 83.5 \\
\hline $\begin{array}{c}\text { Standard } \\
\text { Deviation }\end{array}$ & 11.3 & 7.7 & 13.2 & 7.1 \\
\hline Minimum & 50 & 71.4 & 50 & 71.7 \\
\hline Maximum & 100 & 100 & 100 & 98.3 \\
\hline
\end{tabular}

Table 4: Individual Result Summary Wi2016 (90 min).

\begin{tabular}{|c|c|c|c|c|}
\hline $\begin{array}{c}\text { Score } \\
\text { (\% Basis) }\end{array}$ & $\begin{array}{c}\text { Answer } \\
\text { Sheet }\end{array}$ & $\begin{array}{c}\text { Part } \\
\text { Marks }\end{array}$ & MB & $\begin{array}{c}\text { Test } \\
\text { Total }\end{array}$ \\
\hline Average & 73.3 & 84.1 & 42.5 & 74.5 \\
\hline $\begin{array}{c}\text { Standard } \\
\text { Deviation }\end{array}$ & 15.8 & 14.1 & 25 & 14 \\
\hline Minimum & 33.3 & 37.5 & 0 & 39.3 \\
\hline Maximum & 100 & 100 & 100 & 100 \\
\hline
\end{tabular}

Table 5: Team Result Summary Wi2016 (30 min).

\begin{tabular}{|c|c|c|c|c|}
\hline $\begin{array}{c}\text { Score } \\
\text { (\% Basis) }\end{array}$ & $\begin{array}{c}\text { Answer } \\
\text { Sheet }\end{array}$ & $\begin{array}{c}\text { Part } \\
\text { Marks }\end{array}$ & MB & $\begin{array}{c}\text { Test } \\
\text { Total }\end{array}$ \\
\hline Average & 93.3 & 90.0 & 80.0 & 89.5 \\
\hline $\begin{array}{c}\text { Standard } \\
\text { Deviation }\end{array}$ & 8.3 & 20.0 & 22.5 & 9.2 \\
\hline Minimum & 66.7 & 50.0 & 25 & 69.6 \\
\hline Maximum & 100 & 100 & 100 & 100 \\
\hline
\end{tabular}

\subsection{Student Reaction to Team Midterm}

Most students were happy to have the opportunity to improve their individual score by participating in a team midterm. This was especially true for the Fa15 version where students felt more time pressure for the individual exam. It was seen as an opportunity to increase their grade. After the team midterm, students had several types of reactions. Reactions were consistent with those noted by the University of Alberta Mathematics Department and the UBC Physics Department:

- "It showed me where I made all my mistakes..."

- "I knew I had done really well..."

- "It was good to get the feedback on the questions"

- "I was surprised at how much easier it was to finish with a team"

- "I learned about how my team thinks and works together"

\subsection{Instructor Observations of Collaboration}

Teams appeared to select a strategy to complete the team midterm and many had discussed this in advance. Strategies included:
- $\quad$ Divide and conquer - the exam questions were passed around to team members and each member completed some and then they were reviewed as time permitted.

- Discussion - questions were debated and the answer decided, recorded and then justified. Sometimes voting was employed.

All teams finished the team midterm in less than 30 minutes. Almost all individuals improved their mark as shown in Figure 1. The Cohen effect size was calculated as $d=1.6$ for the Fa15 cohort and $d=1.3$ for the Wi16 cohort using the individual results as the control group.

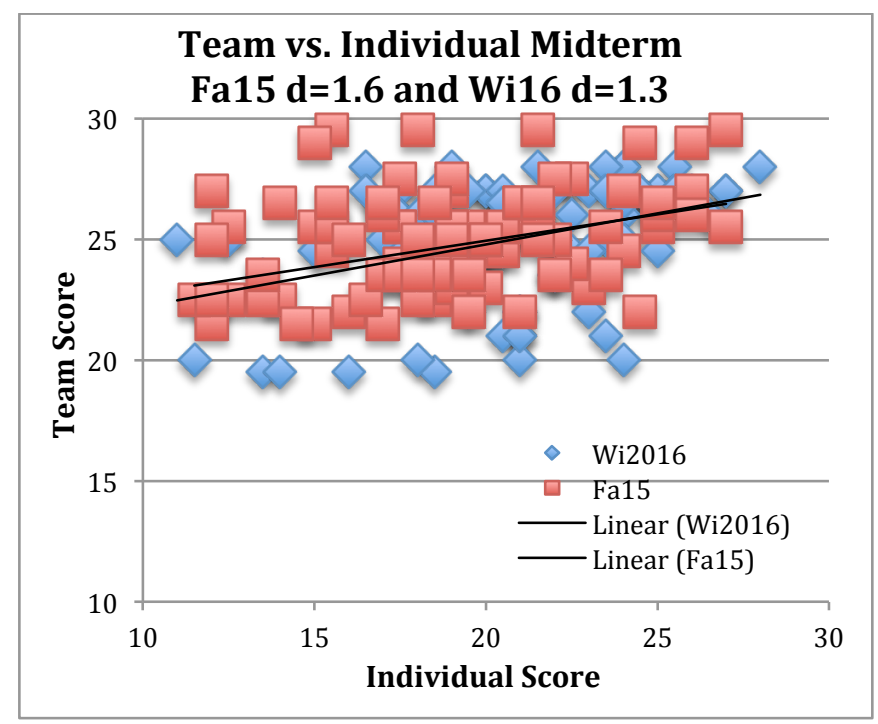

Figure 1. Midterm Mark Improvements

\subsection{Instructor Observations of Individual Part}

Not all students finished the individual portion for either cohort, more finished when the additional time was provided. Additional time was provided for the Wi16 cohort as a direct result of Fa15 cohort feedback on the time pressure of the midterm. Some of the students did not do the pre-read and this may have contributed to the perceived time constraint. The Wi16 cohort generally did not indicate the exam was too long, but some students still ran out of time.

\section{CONCLUSIONS}

In general, students and instructors were satisfied with the results of the two-part midterm. Students were provided with an opportunity to collaborate, to discuss the midterm, to share methods and strategies for solving the questions, and to obtain immediate peer feedback on their work. Midterm follow up was rapid because of it's structure and marking plan. This and the review of problem areas added to the formative aspects of the midterm. Summative assessment information was provided and the 
instructors were able to pin point and rapidly readdress topics posing challenges to students.

\subsection{Feedback and Professional Skill Development}

In addition to meeting instructor summative and student formative requirements two-part midterm assessment provides effective and timely developmental feedback to students regarding collaborative skills, and fosters professional skill development including consensus, teamwork, debate, discussion and group time management. Students are already prepared for the midterm and their preparation carries over to the team discussion of misterm questions. Comparison of answers and strategies requires metacognitive reflection.

\subsection{Summative Assessment Requirements Met}

The individual portion of the midterm meets the summative assessment requirements and the formative feedback to instructors regarding student thinking remains available. This information informs the revision of existing and the preparation of additional learning activities.

\section{Acknowledgements}

We acknowledge with thanks the encouragement and support given throughout the pilot by Dr. Norma Nocente, and the Centre for Teaching, the Fa2015, Wi2016 cohorts of the Chemical Engineering - Introductory Design course (CHE 464), and our teaching colleagues Mr. Doug Colborne, Mr. Len Church and Dr. Arvind Rajendran for their support of this work.

\section{References}

[1] B. Bloom, M. Englehart, E. Furst, W. Hill, and D. Krathwohl, (1956), "Taxonomy of Educational Objectives, the Classification of Educational Goals, Handbook I: Cognitive Domain", In Anderson. L.W., Sosniak, L.A, (Eds.), (1994). "Bloom's Taxonomy: A Forty Year Retrospective", The National Society For the Study of Education : Chicago, 200 pp. \{ISBN: 978-0077-5762\}

[2] J.B. Biggs, "What the Student Does: teaching for enhanced learning. Higher Education Research and Development", 18(1), (1999) 57-75.

[3] J.B Biggs, "Teaching for Quality Learning at University: What the Student Does". Buckingham; Philadelphia, PA: Society for Research into Higher Education : Open University Press (2003).
[4] J.B. Biggs and C.S. Tang, Society for Research into Higher Education, "Teaching for Quality Learning at University: What the Student Does." Maidenhead: McGraw-Hill Education (2011).

[5] Committee on Developments in the Science of Learning with additional material from the Committee on Learning Research and Educational Practice; Board on Behavioral, Cognitive, and Sensory Sciences; Division of Behavioral and Social Sciences and Education; National Research Council, How People Learn: Brain, Mind, Experience, and School: Expanded Edition (National Academy Press, 2000)

[6] B. Gilley and B. Clarkston, "Collaborative testing: Evidence of learning in a controlled in-class study of undergraduate students," J. Coll. Sci. Teach. (2014).

[7] John Hattie, "The Black Box of Tertiary Assessment: An Impending Revolution”, In L. H. Meyer, S. Davidson, H. Anderson, R. Fletcher, P.M. Johnston, \& M. Rees (Eds.), Tertiary Assessment \& Higher Education Student Outcomes: Policy, Practice \& Research (2009) pp.259-275. Wellington, New Zealand: Ako Aotearoa

[8] P. Heller, R. Keith, and S. Anderson, “Teaching problem solving through cooperative grouping. Part 1: Group versus individual problem solving," Am. J. Phys. 60, (1992) pp. 627-636.

[9] P. Heller and M. Hollabaugh, "Teaching problem solving through cooperative grouping. Part 2: Designing problems and structuring groups," Am. J. Phys. 60, (1992) pp. 637644. http://dx.doi.org/10.1119/1.17117

[10] Marnie V. Jamieson, “Application of Blended and Active Learning to Chemical Engineering Design Instruction", MSc Thesis, University of Alberta (2016)

[11] Metcalfe, J., \& Finn, B., "Evidence that judgments of learning are causally related to study choice", Psychonomic Bulletin \& Review, 15, (2008) 174-179.

[12] L. Resnick and L. Klopfer, (Eds.) "Toward the Thinking Curriculum: Current Cognitive Research", Alexandria, VA: Association for Supervision and Curriculum Development. (1989).

[13]Leonora G. Weil, Stephen M. Fleming, Iroise Dumontheil, Emma J. Kilford, Rimona S. Weil, Geraint Rees, Raymond J. Dolan, Sarah-Jayne Blakemore, "The development of metacognitive ability in adolescence", Consciousness and Cognition 22 (2013) 264-271.

[14] Carl E. Wieman, Georg W. Rieger, and Cynthia E. Heiner, "Physics Exams that Promote Collaborative Learning," The Physics Teacher 52, 51 (2014); http://dx.doi.org/10.1119/1.4849159 